INTERVENTIONAL CARDIOLOGY AND SURGERY

\title{
Pharmacological modulation of the ATP sensitive potassium channels during repeated coronary occlusions: no effect on myocardial ischaemia or function
}

\author{
T B Lindhardt, N Gadsbøll, H Kelbæk, K Saunamäki, J K Madsen, P Clemmensen, B Hesse, \\ S Haunsø
}

Heart 2004;90:425-430. doi: 10.1136/hrt.2002.006114

See end of article for authors' affiliations ......................

Correspondence to: Dr Tommi Bo Lindhardt, Department of Cardiology, Bispebjerg Hospital, Copenhagen University Hospital, 23 Bispebjerg Bakke, DK-2400

Copenhagen, Denmark; lindhard+@dadlnet.dk

Accepted

2 September 2003
Background: Repeated episodes of myocardial ischaemia may lead to ischaemic preconditioning. This is believed to be mediated by the ATP sensitive potassium channels.

Objective: To examine the effect of pharmacological modulation of the ATP sensitive potassium channels during repeated coronary occlusions.

Design: Double blind, double dummy study.

Methods: 38 patients with a proximal stenosis of the left anterior descending coronary artery and no visible coronary collateral vessels underwent three identical 90 second balloon occlusions, each followed by five minutes of reperfusion. The patients were randomised to pinacidil $25 \mathrm{mg}$, glibenclamide $10.5 \mathrm{mg}$, or matching placebo 90 minutes before the start of the procedure. Myocardial ischaemia was measured by continuous monitoring of ECG ST segment changes. Changes in left ventricular function were recorded with a miniature radionuclide detector, and angina was scored on the Borg scale.

Results: In all patients the first balloon occlusion led to significant ST segment elevation, a clear decrease in left ventricular ejection fraction, and angina pectoris. This response was not attenuated at the second or third balloon occlusion, either in the placebo group or in the patients pretreated with pinacidil or glibenclamide.

Conclusions: Under the given experimental conditions, this randomised and double blind study did not support the view that the human myocardium has an intrinsic protective mechanism that is activated by short lasting episodes of ischaemia.

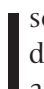
chaemic preconditioning in its classical form has been documented in all animal models studied so far, and there are observations suggesting that this protective mechanism may operate in humans as well. ${ }^{1}$ Various hypotheses have been proposed to explain how the heart becomes tolerant to repeated episodes of ischaemia. Opening of the ATP sensitive potassium channels on the sarcolemma of cardiac myocytes is thought to shorten the duration of the action potential in the myocyte and vascular smooth muscle, leading to a reduction in intracellular calcium. This results in reduced contractile performance and vasodilatation, both of which may protect the heart by reducing cardiac energy requirement and enhancing coronary flow. ${ }^{2}$ There is recent evidence that another ATP sensitive potassium channel isoform located on the mitochondrial inner membrane may also play a role in ischaemic preconditioning by optimising energy production. $^{3}$

Percutaneous transluminal coronary angioplasty (PTCA) can be used as an experimental model for inducing controlled episodes of myocardial ischaemia in humans, and several investigators have attempted to induce ischaemic preconditioning during PTCA by exposing patients to repetitive cycles of balloon inflation and deflation. $^{4-23}$

To examine a possible role of ATP sensitive potassium channels in the development of preconditioning, we produced repeated coronary occlusions in patients undergoing coronary angioplasty. The patients were randomised in a double blind fashion to treatment with either an ATP sensitive potassium channel opener (pinacidil), a potassium channel blocker (glibenclamide), or placebo.

\section{METHODS}

\section{Patients}

Forty five patients with chronic stable angina undergoing elective PTCA of a stenotic lesion (50-90\%) in the left anterior descending coronary artery (LAD) were included in the study.

Exclusion criteria were a history of Q wave myocardial infarction, episodes of angina pectoris 24 hours before the PTCA procedure, angiographically visible coronary collateral vessels, cardiac arrhythmias, a left ventricular ejection fraction (LVEF) of $<45 \%$, left ventricular hypertrophy or bundle branch block on the ECG, ST segment abnormalities at rest, diabetes mellitus, and systemic hypertension. All patients had normal hepatic and renal function.

The study was approved by the local ethics committee (KF 02-133/96). Patients were recruited after written informed consent had been obtained.

\section{Study design}

The patients were randomised in a double blind, double dummy fashion to receive either a capsule of $25 \mathrm{mg}$ pinacidil, a tablet of $10.5 \mathrm{mg}$ glibenclamide, or a matching placebo. To neutralise the blood glucose lowering effect of glibenclamide, patients in the glibenclamide arm received a continuous infusion of $10 \%$ glucose throughout the study. Patients

Abbreviations: $L A D$, left anterior descending coronary artery; LVEF, left ventricular ejection fraction; PTCA, percutaneous transluminal coronary angioplasty 


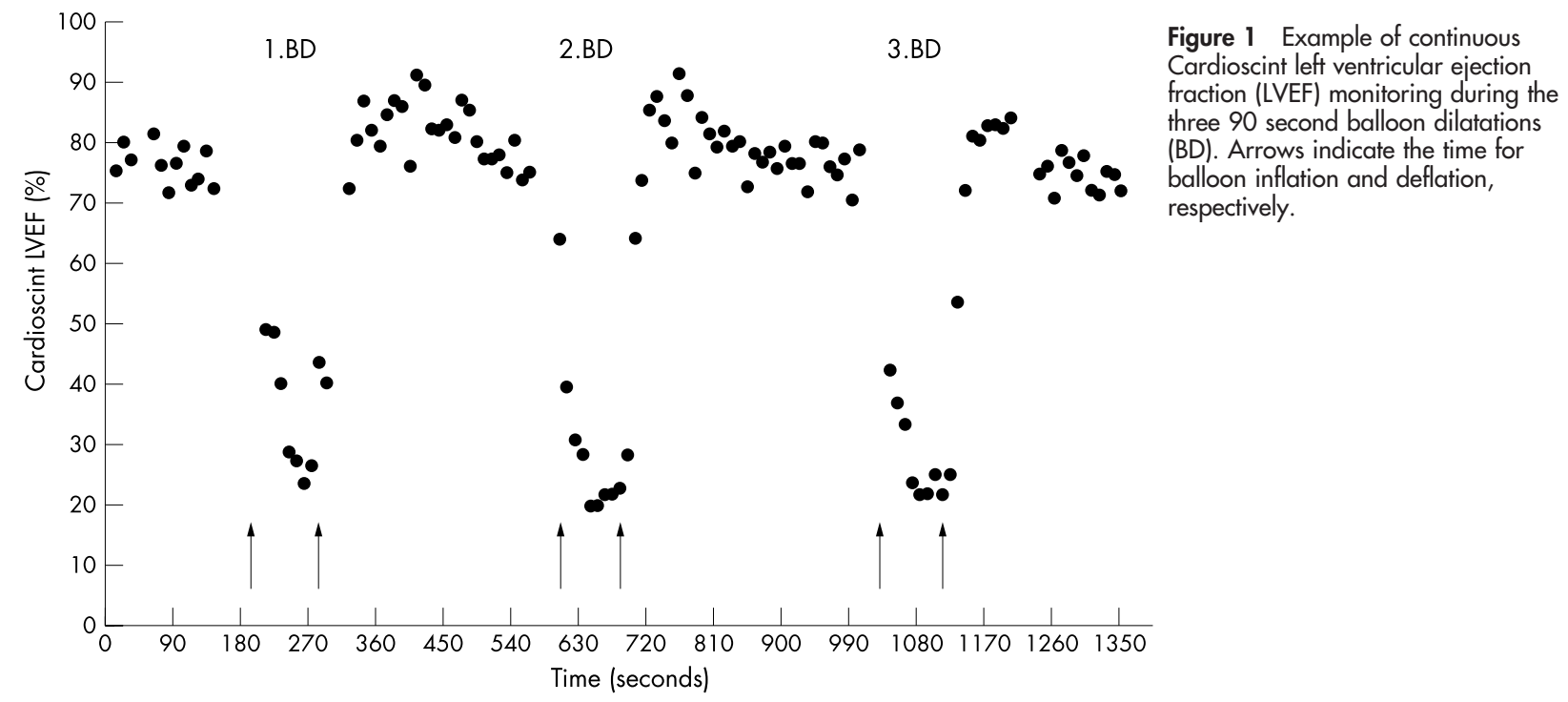

randomised to pinacidil or placebo received an infusion of saline. The intravenous infusions were also given in a double blind fashion.

The patients underwent coronary angioplasty 90 minutes after oral administration of the study drug. All patients had three balloon dilatations using the same balloon with unchanged intracoronary position of the balloon and identical inflation pressure at each inflation. Each balloon dilatation lasted 90 seconds, followed by five minutes of reperfusion or longer when the ST segment had not returned to baseline.

\section{Coronary angioplasty}

All patients were studied after an overnight fast and were premedicated with $10 \mathrm{mg}$ of diazepam 30 minutes before the procedure. Coronary angioplasty was undertaken using the standard transfemoral approach. ${ }^{24}$ The diameter of the guide wire ranged from $0.010-0.014$ inches $(0.25-0.36 \mathrm{~mm})$ and the diameter of the inflated balloon ranged from $2.5-3.5 \mathrm{~mm}$, with length ranging from $13-30 \mathrm{~mm}$. Immediately after each balloon deflation and during the reperfusion period, the balloon was retracted from the coronary artery to the guiding catheter to allow unhindered coronary reperfusion.

After the three balloon dilatations, coronary angiography was completed on the basis of the specific needs of the individual patient, with stent implantation in 35 patients $(92 \%)$ and abolition of the stenosis in all.

\section{Myocardial ischaemia}

Continuous 12 lead ST segment monitoring was done using the Mortara ELI ST-100 monitor (Mortara Instruments, Milwaukee, Wisconsin, USA). ${ }^{25}{ }^{26}$ This is an ECG machine with an ST segment monitoring option. Throughout the monitoring session it continuously acquires and repeatedly stores 12 lead ECGs.

A baseline ECG was acquired before the PTCA procedure. During each balloon dilatation the ECG with the maximum ST segment deviation in a single lead was selected for analysis, together with an ECG recorded at the end of the subsequent five minute reperfusion period. For each ECG, two variables were analysed: STmax, defined as the peak amplitude of ST segment deviation in the lead with the maximum ST segment deviation; and STsum, defined as the total magnitude of ST segment deviation averaged over 12 leads in the ECG recorded at the time of the STmax.
To estimate the amount of myocardium that was rendered ischaemic during the balloon inflation we used a modification of the jeopardy score developed by Califf and colleagues. ${ }^{27}$

\section{Angina pectoris}

After each balloon dilatation the patients graded the intensity of chest pain using Borg's numerical scale. ${ }^{28}$

\section{Left ventricular function}

To monitor changes in left ventricular function during coronary angioplasty we used the Cardioscint detector system (Oakfield Instruments, Oxford, UK). The Cardioscint is a non-imaging, miniature nuclear detector developed for continuous monitoring of left ventricular function. After labelling of the patient's blood with $800 \mathrm{MBq} 99 \mathrm{~m}$-technetium the detector was placed over the left ventricle. The detector can be fixed to the patient's chest wall throughout the monitoring session, as previously described. ${ }^{29}$

Data acquisition was done using a 10 second acquisition period. This acquisition time made it possible to track short lasting changes in LVEF during the PTCA procedure, as previously described in detail. ${ }^{24}$ LVEF was measured after insertion of the guiding catheter and intracoronary positioning of the guide wire (baseline); during each balloon dilatation; and at the end of the reperfusion period with the guide wire in situ (fig l).

\section{Blood glucose}

Venous blood samples for measurement of glucose concentrations were drawn before the first balloon dilatation and immediately after the PTCA procedure.

\section{Blood pressure}

Aortic pressure was measured continuously through the angioplasty guiding catheter. Baseline values were obtained after placement of the guiding catheter and the guide wire. PTCA values were obtained at the end of the balloon dilatations, and post-PTCA values were obtained at the end of the reperfusion periods.

\section{Data processing and statistical analysis}

The recorded ECG data and Cardioscint data were downloaded and processed post hoc as previously described. ${ }^{25} 2930$

Analysis of variance, Student's $t$ test, $\chi^{2}$ test, and Fisher's exact test were used as appropriate. A probability value of 
Table 1 Patient characteristics

\begin{tabular}{lllll}
\hline & $\begin{array}{l}\text { Placebo } \\
(\mathbf{n}=14)\end{array}$ & $\begin{array}{l}\text { Pinacidil } \\
(\mathbf{n = 1 4 )}\end{array}$ & $\begin{array}{l}\text { Glibenclamide } \\
(\mathbf{n = 1 0 )}\end{array}$ & p Value \\
\hline Men/women (\% men) & $11 / 3(79 \%)$ & $10 / 4(71 \%)$ & $8 / 2(80 \%)$ & NS \\
Age (years) & $59(8)$ & $59(9)$ & $53(9)$ & NS \\
AMl & $8(57 \%)$ & $7(50 \%)$ & $5(50 \%)$ & NS \\
CCS (range) & $2.6(2$ to 3) & $2.4(1$ to 3) & $2.3(1$ to 3) & NS \\
Pre-PTCA stenosis (\%) & $69(10)$ & $78(12)$ & $75(9)$ & NS \\
Jeopardy score (range) & $5.8(4$ to 6) & $5.4(4$ to 6) & $5.6(4$ to 6$)$ & NS \\
One vessel disease & $9(64 \%)$ & $9(64 \%)$ & $8(80 \%)$ & NS \\
Dilatation pressure (atm) & $8(2)$ & $9(4)$ & $8(3)$ & NS \\
\hline
\end{tabular}

Values are mean (SD), $\mathrm{n}(\%)$, or $\mathrm{n}$ (range).

AMI, acute myocardial infarction; atm, atmosphere; CCS, Canadian Cardiovascular Society functional

classification; PTCA, percutaneous transluminal coronary angioplasty.

$\mathrm{p}<0.05$ was considered significant. Data are expressed as mean (SD).

\section{RESULTS}

Patients

Data from seven patients had to be excluded from the analysis, for the following reasons. On the day of the PTCA two patients had collateral vessels which had not been visible on the referral angiogram, and in another the culprit stenosis was judged not to be flow limiting. One patient developed ventricular fibrillation during the procedure, one developed atrial fibrillation, one had total occlusion of the LAD which could not be reopened, and in one the nuclear detector could not be positioned adequately. The study population thus comprised 38 patients (nine women and 29 men), with a mean age of 57 (9) years.

There was no difference between the three groups with regard to sex, age, previous non-Q myocardial infarction, Canadian Cardiovascular Society functional classification, anti-ischaemic treatment, number of vessels affected by coronary disease, the severity of the LAD stenosis, and the amount of myocardium rendered ischaemic during balloon occlusion (table 1).

Mean balloon pressure was similar in the placebo, pinacidil, and the glibenclamide treated patients, at 8 (4) $v$ 9 (4) $\vee 8$ (3) atm (NS).

The blood glucose concentration before and after the PTCA treatment did not change, either within or between the three groups: placebo 5.1 (0.8) $\vee 4.7$ (1.3) mmol/l; pinacidil 5.6 (0.9) $v 5.8$ (1) mmol/l; glibenclamide 5.4 (1.4) $v 5.4$ (2.2) $\mathrm{mmol} / \mathrm{l}$.

On the day of the PTCA procedure, the patients received their normal morning drug treatment: 37 received aspirin, $24 \beta$ receptor blockers, 18 calcium antagonists, 12 long acting nitrates, five angiotensin converting enzyme inhibitors, and five diuretics. Three patients received triple therapy with $\beta$ receptor blockers, calcium antagonists, and long acting nitrates; 11 received combination therapy with two anti-ischaemic drugs, and 23 were treated with only one anti-ischaemic drug. No patient received sublingual or intravenous nitrates during the procedure.

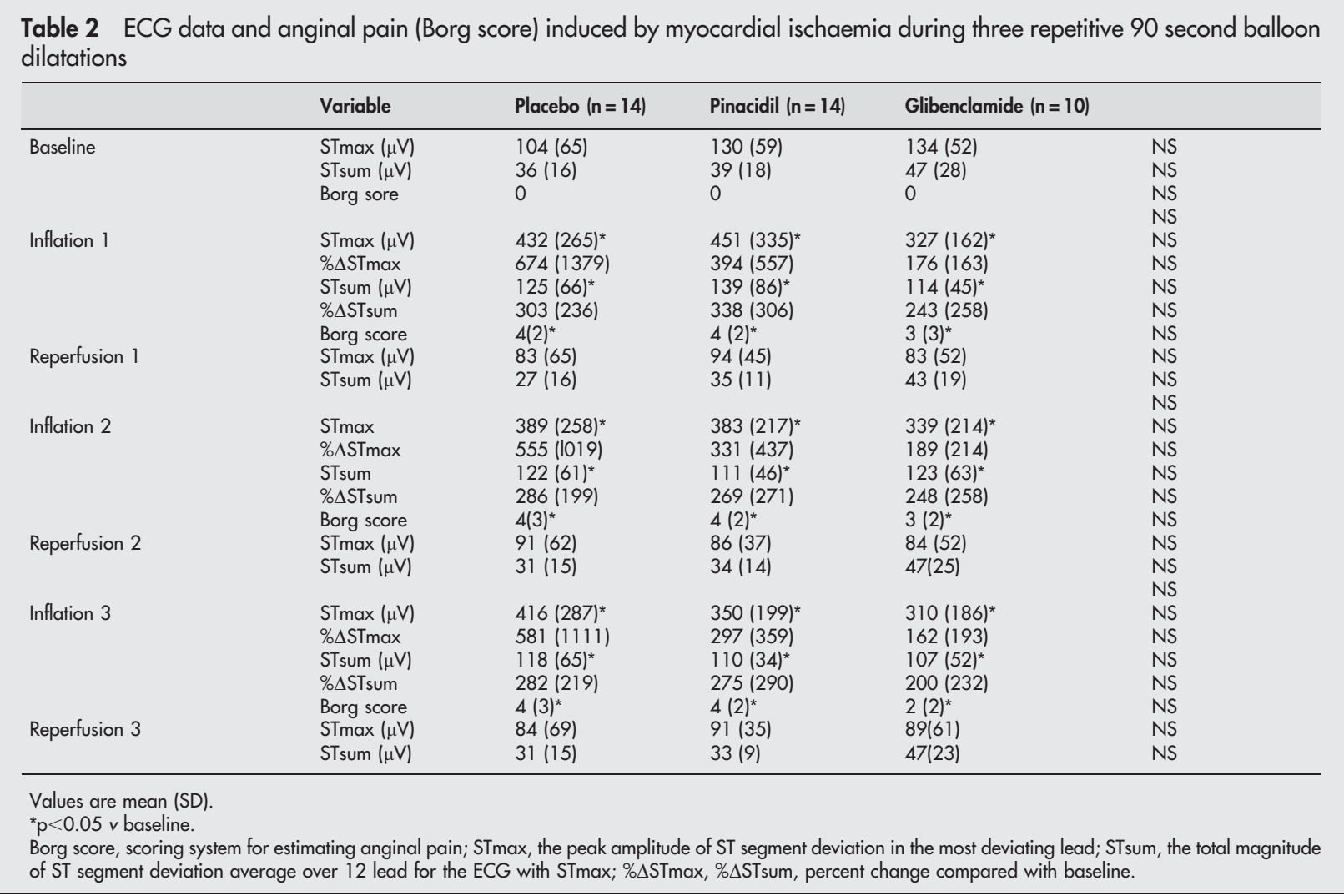


Table 3 Left ventricular ejection fraction, heart rate, and blood pressure during three repetitive 90 second balloon dilatations

\begin{tabular}{|c|c|c|c|c|c|}
\hline & Variable & Placebo $(n=14)$ & Pinacidil ( $n=14$ ) & Glibenclamide ( $n=10$ ) & \\
\hline \multirow[t]{4}{*}{ Baseline } & LVEF & $0.57(0.09)$ & $0.62(0.10)$ & $0.58(0.10)$ & NS \\
\hline & $\mathrm{MAP}(\mathrm{mm} \mathrm{Hg})$ & $98(12)$ & $96(15)$ & $102(21)$ & NS \\
\hline & HR (beats/min) & $66(14)$ & $71(16)$ & $61(10)$ & NS \\
\hline & $\operatorname{RRP}\left(10^{3} \mathrm{~mm} \mathrm{Hg} / \mathrm{min}\right)$ & $8.1(2.1)$ & $9.2(3.7)$ & $8.2(2.6)$ & NS \\
\hline \multirow[t]{5}{*}{ Inflation 1} & LVEF & $0.33(0.12)^{*}$ & $0.37(0.09)^{*}$ & $0.36(0.14)^{*}$ & NS \\
\hline & $\% \Delta \mathrm{LVEF}$ & $43(18)$ & $41(14)$ & $37(21)$ & NS \\
\hline & MAP (mm Hg) & $107(20)^{*}$ & 100 (19) & $101(22)$ & NS \\
\hline & $\mathrm{HR}$ (beat/min) & $70(14)$ & $73(20)$ & $68(12)$ & NS \\
\hline & $\operatorname{RRP}\left(10^{3} \mathrm{~mm} \mathrm{Hg} / \mathrm{min}\right)$ & $9(2.5)$ & $8.5(3.1)$ & $8.3(2.3)$ & NS \\
\hline \multirow[t]{4}{*}{ Reperfusion 1} & LVEF & $0.60(0.09)$ & $0.65(0.11)$ & $0.60(0.10)$ & NS \\
\hline & MAP (mm Hg) & $107(16)$ & $106(17)$ & 102 (19) & NS \\
\hline & HR (beats/min) & $63(12)$ & $68(16)$ & $60(9)$ & NS \\
\hline & $\operatorname{RRP}\left(10^{3} \mathrm{~mm} \mathrm{Hg} / \mathrm{min}\right)$ & $8.8(2.9)$ & $9.6(2.9)$ & $8.0(2.4)$ & NS \\
\hline \multirow[t]{5}{*}{ Inflation 2} & LVEF & $0.32(0.11)^{*}$ & $0.36(0.10)^{*}$ & $0.37(0.13)^{*}$ & NS \\
\hline & $\% \Delta$ LVEF & $44(15)$ & $42(15)$ & $49(36)$ & NS \\
\hline & $\mathrm{MAP}(\mathrm{mm} \mathrm{Hg})$ & $112(21)^{*}$ & $104(23)^{*}$ & $102(20)$ & NS \\
\hline & HR (beats/min) & $69(14)$ & $70(16)$ & $61(12)$ & NS \\
\hline & $\operatorname{RRP}\left(10^{3} \mathrm{~mm} \mathrm{Hg} / \mathrm{min}\right)$ & $9.3(2.9)^{*}$ & $9.4(4.0)$ & $7.6(2.6)$ & NS \\
\hline \multirow[t]{4}{*}{ Reperfusion 2} & LVEF & $0.60(0.09)$ & $0.65(0.10)$ & $0.60(0.10)$ & NS \\
\hline & $\mathrm{MAP}(\mathrm{mm} \mathrm{Hg})$ & $109(18)$ & $106(17)$ & $102(22)$ & NS \\
\hline & HR (beats/min) & 60 (10) & $67(16)$ & 59 (10) & NS \\
\hline & $\operatorname{RRP}\left(10^{3} \mathrm{~mm} \mathrm{Hg} / \mathrm{min}\right)$ & $8.6(2.7)$ & $9.5(3)$ & $7.9(2.6)$ & NS \\
\hline \multirow[t]{5}{*}{ Inflation 3} & LVEF & $0.33(0.12)^{*}$ & $0.36(0.10)^{*}$ & $0.37(0.12)^{*}$ & NS \\
\hline & $\% \Delta$ LVEF & $42(17)$ & $43(14)$ & $45(34)$ & NS \\
\hline & $\mathrm{MAP}(\mathrm{mm} \mathrm{Hg})$ & $111(23)^{*}$ & 104 (19) & $106(24)$ & NS \\
\hline & HR (beats/min) & $67(14)$ & $67(16)$ & $62(12)$ & NS \\
\hline & $\operatorname{RRP}\left(10^{3} \mathrm{~mm} \mathrm{Hg} / \mathrm{min}\right)$ & $9.1(3)$ & $8.7(3.0)$ & $8.0(2.7)$ & NS \\
\hline \multirow[t]{4}{*}{ Reperfusion 3} & LVEF & $0.59(0.10)$ & $0.64(0.10)$ & $0.60(0.10)$ & NS \\
\hline & $\mathrm{MAP}(\mathrm{mm} \mathrm{Hg})$ & $110(16)$ & $105(22)$ & $103(22)$ & NS \\
\hline & HR (beats/min) & $61(10)$ & $63(14)$ & $59(10)$ & NS \\
\hline & $\operatorname{RRP}\left(10^{3} \mathrm{~mm} \mathrm{Hg} / \mathrm{min}\right)$ & $8.7(2.5)$ & $8.8(2.7)$ & $8.0(2.9)$ & NS \\
\hline
\end{tabular}

Values are mean (SD).

${ }^{*} \mathrm{p}<0.05 v$ baseline.

$H R$, heart rate; LVEF, left ventricular ejection fraction; \% $\Delta \mathrm{LVEF}$, per cent change $v$ baseline; MAP, mean arterial pressure; RRP, heart rate $\times$ systolic blood pressure.

\section{Myocardial ischaemia}

The ECG ST segment changes during the PTCA procedure are illustrated in table 2 .

In all three groups, balloon occlusions led to significant ST segment elevation with return to baseline value after balloon deflation.

In the placebo and pinacidil treated patients, there was a non-significant tendency to a reduction in the ischaemic indices during the second and third balloon occlusion as compared with the first. No such trend was present in the glibenclamide treated patients. There was no change in the angina score on any of the balloon dilatations in any of the groups.

\section{Myocardial function}

Table 3 shows the changes in myocardial function during the three balloon occlusions. LVEF decreased significantly during each occlusion in all the patients, with return to baseline values during the reperfusion period. There was no difference in the decrease in LVEF between the three occlusions within a single group. The decrease in LVEF did not differ significantly between the groups.

The heart rate-pressure product (RPP)-an index for myocardial oxygen consumption-increased during the three balloon occlusions in the placebo group, although this was only significant during the second occlusion $(\mathrm{p}=0.02)$. The RPP tended to decrease during the first and the third occlusion in the pinacidil treated patients, but none of the changes was significant. In the glibenclamide treated patients the changes in RPP were minor and non-significant.

\section{DISCUSSION}

Several investigators have used PTCA to expose patients to repetitive cycles of ischaemia and reperfusion in an attempt to induce preconditioning. Some studies have been observational $^{4-11}$ while in others various pharmacological interventions have been used to explore this putative protective mechanism. ${ }^{12-22}$ With few exceptions these have all shown a preconditioning-like adaptation to ischaemia, as judged primarily by ST segment recordings during coronary occlusions. ${ }^{5-10} 20$

\section{The present study}

In an observational study on left ventricular function during PTCA we have previously reported that two balloon inflations led to an attenuation of the decrease in LVEF and ECG signs of myocardial ischaemia during the second balloon inflation, suggesting that the myocardium became increasingly resistant to ischaemia. ${ }^{24}$ However, in the present placebo controlled, double blind study, carried out according to a strict experimental protocol and including only patients with LAD disease and no angiographically visible coronary collateral vessels, we were unable to detect such a pattern in any of the three treatment groups, despite a notable response to balloon inflation in all patients.

\section{Collateral coronary circulation}

Recruitment of collaterals is probably the main confounding variable when trying to establish whether preconditioning can be induced by successive balloon inflations in the course of PTCA.

Several PTCA studies have examined the protective role of collaterals by ipsilateral and contralateral coronary injection of contrast medium ${ }^{53}$ or radioactive tracers ${ }^{31}$; by measurement of cardiac vein flow ${ }^{4}$ and blood flow velocity in the contralateral coronary artery ${ }^{19}{ }^{21}$; by contrast echocardiography of the myocardium supplied by the balloon occluded vessel $^{10}$; or by assessment of intracoronary occlusion pressure. ${ }^{20}$ These studies showed that collaterals-which can be categorised as visible spontaneously occurring vessels or as 
recruitable (that is, "dormant") collaterals which only become functional when the recipient artery is occludedmay play a major role in the adaptation to myocardial ischaemia, especially in patients with tight stenotic lesions. ${ }^{31}$ Kyriakidis and colleagues undertook four successive coronary balloon dilatations in 24 patients with stenosis of the LAD artery and assigned the patients to three groups, according to the extent of the collateral circulation during the initial coronary occlusion. ${ }^{32}$ ST segment elevation and the severity of angina were unchanged from the first to the fourth occlusion in patients with either absent or high grade collateral circulation, but decreased significantly in those with a low grade collateral circulation-an effect that may easily be mistaken for preconditioning.

Several investigators have acknowledged that collaterals may have influenced their results, but state at the same time that preconditioning played a role in the observed adaptation to ischaemia above and beyond the influence of collaterals. ${ }^{5} 102023$

We excluded patients with spontaneously visible collaterals on the pre-PTCA angiogram, but did not control for recruitment of collaterals during the three balloon occlusions, which is a limitation of the study. We cannot exclude the possibility that some patients may have had recruitable collaterals, but these were not of such functional importance that they protected the myocardium from becoming ischaemic, as evidenced by the pronounced ischaemic reaction in each individual patient.

\section{Duration of the balloon occlusion}

In animals, induction of preconditioning is critically dependent on the duration of the initial ischaemic stimulus and the subsequent reperfusion period. ${ }^{33}$ A very brief stimulus may be insufficient to confer preconditioning, whereas protection may be lost if the duration of the ischaemic episodes is too long. ${ }^{34}$ Also in humans there appears to be a rather narrow time window for the preconditioning stimulus.

Deutsch and colleagues were among the first to show that preconditioning may be induced during coronary angioplasty. ${ }^{4}$ They used 90 seconds of balloon occlusion of the LAD coronary artery as the ischaemic stimulus and found that the intensity of anginal pain, the magnitude of ST segment shift, myocardial lactate production, and mean pulmonary artery pressure were lower during the second than during the first balloon occlusion, with no indication of collateral vessel recruitment, as judged by measurement of cardiac vein flow.

Kerensky et al,,$^{13}$ Claeys et al,,$^{15}$ and Lim et al ${ }^{35}$ also found that 90 seconds of balloon occlusion was enough to induce ischaemic preconditioning using an angina score and ST segment changes as end points. Other investigators have used 120 seconds of ischaemia in their attempt to induce preconditioning during PTCA. ${ }^{12}$ 16-22

Only one study has tried explicitly to define the optimal duration of preconditioning stimuli. Matsubara and colleagues showed that 180 seconds but not 60 seconds of myocardial ischaemia were associated with preconditioning. ${ }^{23}$

At present there is no consensus on how long the ischaemic stimulus should be to give the most effective preconditioning response. We used 90 seconds of balloon occlusion, based on our previous experience. ${ }^{24}$

\section{Myocardium at risk}

Another confounding factor is the myocardial area at riskthat is, the amount of myocardium that becomes ischaemic on each balloon inflation. We only included patients with LAD disease as we had previously observed that balloon occlusions of the LAD gave rise to a much more pronounced ischaemic response than occlusions of the right or circumflex coronary artery. ${ }^{24}$ We anticipated that the induction of preconditioning was more likely the greater the area of myocardium at risk. However, in a rat model Whittaker and colleagues found a loss of preconditioning induced protection with increasing regions of myocardium at risk. ${ }^{36}$ This paradoxical inverse relation could in theory exist in humans as well, and explain the "no adaptation" response in the present study

\section{Can preconditioning be induced during PTCA?}

It is important to realise that all human studies, including the present one, have used surrogate end points of preconditioning. In its classical sense, preconditioning refers to an infarct limiting mechanism. The mechanisms behind contractile, ECG, metabolic, or other non-classical manifestations of ischaemic preconditioning may be different from those involved in limiting cell death. In addition, preconditioning is influenced by a variety of confounding factors discussed above that are difficult to control for in the setting of coronary angioplasty. ${ }^{37}$ Ongoing treatment with angiotensin converting enzyme inhibitors or glyceryl trinitrate may also influence the preconditioning response, and even standard pretreatment with midazolam or diazepam may cloud the picture through their interaction with GABA receptors. ${ }^{38}$

The plethora of factors that may influence the development of preconditioning during PTCA necessitates controlled study designs. Under the given experimental conditions our present study does not support the view that human myocardium has an intrinsic protective mechanism that is activated upon short lasting episodes of ischaemia.

\section{ACKNOWLEDGEMENTS}

This study was supported by the Danish Heart Foundation and Murermester Laurits Peter Christensen og hustru Kirsten Sigrid Christensens Foundation, Copenhagen, Denmark. We thank LEO Pharma and Hoechst Marion Roussel for providing pinacidil and glibenclamide.

\section{Authors' affiliations}

T B Lindhardt, N Gadsbøll, H Kelbæk, K Saunamäki, J K Madsen,

P Clemmensen, S Haunsø, The Heart Centre, Cardiac Catheterisation Laboratory, Rigshospitalet, Copenhagen University Hospital,

Copenhagen, Denmark

B Hesse, Department of Clinical Physiology and Nuclear Medicine, Rigshospitalet, Copenhagen University Hospital

\section{REFERENCES}

1 Kloner RA, Bolli R, Marban E, et al. Medical and cellular implications of stunning, hibernation and preconditioning. Circulation 1998;97:1848-67.

2 Hearse DJ. Activation of ATP-sensitive potassium channels: a novel pharmacological approach to myocardial protection. Cardiovasc Res 1995;30:1-17.

3 O'Rourke B. Myocardial K-ATP channels in preconditioning. Circ Res 2000;87:845-55.

4 Deutsch E, Berger M, Kussmaul WG, et al. Adaptation to ischemia during percutaneous transluminal coronary angioplasty. Circulation 1990;82:2044-51.

5 Cribier A, Korsatz L, Koning R, et al. Improved myocardial ischemic response and enhanced collateral circulation with long repetitive coronary occlusion during angioplasty: a prospective study. J Am Coll Cardiol 1992;20:578-86

6 Koning R, Cribier A, Korsatz L, et al. Progressive decrease in myocardial ischemia assessed by intracoronary electrocardiogram during successive and prolonged coronary occlusions in angioplasty. Am Heart J 1993;125:56-61.

7 Tomai F, Crea F, Gaspardone A, et al. Mechanisms of cardiac pain during coronary angioplasty. J Am Coll Cardiol 1993;22:1892-6.

8 Dupouy P, Geschwind H, Pelle G, et al. Repeated coronary artery occlusions during routine balloon angioplasty do not induce myocardial preconditioning in humans. J Am Coll Cardiol 1996;27:1374-80.

9 Ylitalo K, Airaksinen J, Ikaheimo M, et al. No evidence for ischemic preconditioning during repeated vessel occlusion in coronary angioplasty. Int J Cardiol 1996;55:227-37.

10 Sakata Y, Kodama K, Kitakaze M, et al. Different mechanisms of ischemic adaptation to repeated coronary occlusion in patients with and without recruitable collaterals circulation. J Am Coll Cardiol 1997;30:1679-86. 
11 Eltchaninoff $\mathbf{H}$, Cribier A, Tron C, et al. Adaptation to myocardial ischemia during coronary angioplasty demonstrated by clinical, electrocardiographic, echocardiographic, and metabolic parameters. Am Heart J 1997; 133:490-6.

12 Tomai F, Crea F, Gaspardone A, et al. Ischemic preconditioning during coronary angioplasty is prevented by glibenclamide, a selective ATP-sensitive $\mathrm{K}^{+}$channel blocker. Circulation 1994;90:700-5.

13 Kerensky RA, Kutcher MA, Braden GA, et al. The effect of intracoronary adenosine on preconditioning during coronary angioplasty. Clin Cardiol 1995;18:91-6

14 Straver BE, Heidland UE, Heintzen MP, et al. Pharmacologic myocardial protection during percutaneous transluminal coronary angioplasty by intracoronary application of dipyridamole: impact on hemodynamic function and left ventricular performance. J Am Coll Cardiol 1996;28:1119-26.

15 Claeys MJ, Vrints CJ, Bosmans JM, et al. Aminophylline inhibits adaptation to ischaemia during angioplasty. Role of adenosine in ischaemic preconditioning. Eur Heart J 1996;17:539-44.

16 Tomai F, Crea F, Gaspardone A, et al. Affect of Al adenosine receptor blockade by bamiphylline on ischaemic preconditioning during coronary angioplasty. Eur Heart J 1996; 17:846-53.

17 Hashimura K, Kijima Y, Matsuura Y, et al. Effect of theophylline on adaptation of the heart to myocardial ischemia during percutaneous transluminal coronary angioplasty in patients with stable angina pectoris. Am J Cardiol 1997;79:475-7

18 Leesar MA, Stoddard M, Ahmed M, et al. Preconditioning of human myocardium with adenosine during coronary angioplasty. Circulation 1997;95:2500-7.

19 Tomai F, Crea F, Gaspardone A, et al. Phentolamine prevents adaptation to ischemia during coronary angioplasty. Role of alpha-adrenergic receptors in ischemic preconditioning. Circulation 1997:96:2171-7.

20 Billinger $M$, Fleisch $M$, Eberli FR, et al. Is the development of myocardial tolerance to repeated ischemia in humans due to preconditioning or to collateral recruitment. J Am Coll Cardiol 1999;33:1027-35.

21 Tomai F, Crea F, Gaspardone A, et al. Effects of naloxone on myocardial ischemic preconditioning in humans. J Am Coll Cardiol 1999;33:1863-9.

22 Leesar MA, Stoddard MF, Manchikalapudi S, et al. Bradykinin-induced preconditioning in patients undergoing coronary angioplasty. J Am Coll Cardiol 1999:34:639-50.

23 Matsubara T, Minatoguchi S, Matsuo H, et al. Three minute, but not one minute, ischemia and nicorandil have a preconditioning effect in patients with coronary artery disease. J Am Coll Cardiol 2000;35:345-51.

24 Lindhardt TB, Kelbæk H, Kyst Madsen J, et al. Continuous monitoring of global left ventricular ejection fraction during percutaneous transluminal coronary angioplasty. Am J Cardiol 1998;81:853-9.
25 Krucoff MW, Wagner NB, Pope JE, et al. The portable programmable microprocessor-driven real-fime 12-lead electrocardiographic monitor: a preliminary report of a new device for the noninvasive detection of successful reperfusion or silent coronary reocclusion. Am J Cardiol 1990;65:143-8.

26 Krucoff MW, Croll MA, Pope JE, et al. Continuously updated 12-lead STsegment recovery analysis for myocardial infarct artery patency assessment and its correlation with multiple simultaneous early angiographic observations. Am J Cardiol 1993;71:145-51.

27 Califf RM, Phillips HR, Hindman MC, et al. Prognostic value of a coronary artery jeopardy score. J Am Coll Cardiol 1985;5:1055-63.

28 Borg G. Psychophysical bases of perceived exertion. Med Sci Sports Exerc 1982; 14:377-81.

29 Lindhardt TB, Hesse B, Gadsb $\$ \|$ N. Monitoring of left ventricular ejection fraction with a miniature, nonimaging nuclear detector: accuracy and reliability over time with special reference to blood labeling. J Nucl Cardiol 1997;4:147-55.

30 Krucoff MW, Pope JE, Bottner RK, et al. Computer-assisted ST-segment monitoring: experience during and after brief coronary occlusion. J Electrocardiol 1987; 20:15-21.

31 Sand NPR, Rehling M, Bagger JP, et al. Functional significance of recruitable collaterals during temporary coronary occlusion evaluated by $99 \mathrm{mTc}-$ sestamibi single-photon emission computerized tomography. J Am Coll Cardiol 2000;35:624-32.

32 Kyriakidis MK, Petropoulakis PN, Tentolouris CA, et al. Relation between changes in blood flow of the contralateral coronary artery and the angiographic extent and function of recruitable collateral vessels arising from this artery during balloon coronary occlusion. J Am Coll Cardiol 1994; 23:869-78

33 Birnbaum Y, Przyklenk K, Kloner RA. The time frame of ischemic preconditioning: is it clinically relevant? J Cardiovasc Pharmacol Ther 1996;1:339-46.

34 Yamasaki K, Fujiwara $\mathrm{H}$, Tanaka $\mathrm{M}$, et al. Preconditioning with 15-minute ischemia extends myocardial infarct size after subsequent 30-minute ischemia in rabbits. Jpn Circ J 1997;61:344-52.

35 Lim R, Laskey WK. Ischemic preconditioning in unstable coronary syndromes: evidence for time dependence. J Am Coll Cardiol 1997;30:1461-5.

36 Whittaker $\mathbf{P}$, Przyklenk K. Reduction of infarct size in vivo with ischemic preconditioning: mathematical evidence for protection via non-ischemic tissue. Basic Res Cardiol 1994;89:6-15.

37 Yellon DM, Dana A. The preconditioning phenomenon. A tool for the scientist or a clinical reality? Circ Res 2000;87:543-50.

38 Zang $\mathrm{HY}, \mathrm{McPherson} \mathrm{BC}$, Liu $\mathrm{H}$, et al. $\mathrm{H}_{2} \mathrm{O}_{2}$ opens mitochondrial K-ATP channels and inhibits GABA receptors via protein kinace $\mathrm{C}$-e in cardiomyocytes. Am J Physiol Heart Circ Physiol 2002;282:H1395-403.

\section{ELECTRONIC PAGES}

\section{Heart Online case reports: www.heartinl.com}

he following electronic only articles are published in conjunction with this issue of Heart.

\section{Left main coronary artery and right pulmonary vein} compression by a large pulmonary artery aneurysm $\checkmark$ Decuypere, M Delcroix, W Budts

Pulmonary artery aneurysms are uncommon and may be associated with significant morbidity and mortality. The unique combination of left main coronary artery and upper right pulmonary vein compression by a large pulmonary artery aneurysm is reported. Furthermore, the aetiology, clinical manifestations, complications, diagnostic approach, and possible therapeutic interventions are briefly discussed.

(Heart 2004;90:e21) www.heartjnl.com/cgi/content/full/90/ $4 / \mathrm{e} 21$

\section{Haemopericardium causing cardiac tamponade: a late complication of pectus excavatum repair M J Barakat, J A Morgan}

A 24 year old man presented to the emergency department with clinical signs of cardiac tamponade requiring emergency surgery. The cause was a sternal wire from a pectus excavatum repair two years previously that had fractured and migrated through the pericardium causing an epicardial injury and a haemopericardium.

(Heart 2004;90:e22) www.heartjnl.com/cgi/content/full/90/ $4 / \mathrm{e} 22$ 